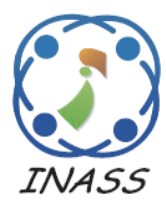

\title{
Robust Interactive PID Controller Design for Medical Robot System
}

\author{
Shaymaa Mahmood Mahdi ${ }^{1 *}$ \\ Safanah Mudheher Raafat ${ }^{1}$ \\ ${ }^{I}$ Control and Systems Engineering Department, University of Technology-Iraq, Baghdad, Iraq \\ * Corresponding author's Email: shaymaa.m.mahdi@uotechnology.edu.iq
}

\begin{abstract}
In this paper, the design and application of robust interactive PID control for a medical robot system is presented. The aim is to solve the problem of precise position tracking required for human walking, using a simple type of control while taking into account the interactions of the systems' input and outputs. The medical robot system can be interpreted as pendulum links to obtain a complete motion of all muscles. Two control actions are required to be applied for the two joints. The interactions of this multivariable system have been examined using the relative gain array (RGA). In this work, PID and Fuzzy PID controllers are implemented with interactions effects. In addition, two other non-conventional types of PID control structures have been considered for comparison, where the RGA cannot be applied. These are the two-degree PID (2DoFPID) and nonlinear PID (NPID) controllers. Simulation results show that in the case of not considering the interaction effects, the Fuzzy PID controller can provide an improvement of $44 \%$ as compared with conventional PID controller. While this improvement has been increased to $70 \%$ with the consideration of interaction effects. Meanwhile, NPID controller shows higher rise and settling times (almost more than 2 seconds for the settling time). While 2DoFPID controller shows difficulty in implementation due to its highly chattered control signals with higher overshoots in the transient response as compared with the results of the interactive Fuzzy PID controller. Finally, robustness against disturbances and system uncertainties has been tested with all the developed controllers. It has been concluded that the interactive Fuzzy PID controller achieves better performance in terms of less ISE, settling time, rise time, and overshoot.
\end{abstract}

Keywords: Medical robot system, Fuzzy PID, Nonlinear PID, Two-degree PID, Relative gain array.

\section{Introduction}

An attractive phenomenon is a human movement where the humans have a changeable ability of place position, where scamper, running, and walking are a point of view to be considered. From the beginning of hominins, movement is considered an observable thing for humans, despite still the matter of the splinted way of our two-legged walking is conjecture. Sophisticated environments, tools, and equipment were built by humans within a very skilled manner to use in the new community. Humanoid robots inherently have a major similarity with morphology humanlike and motion capabilities with in human environments [1]. The multivariable robotic system has high interaction effects between the system's inputs and outputs. These are usually considered as inhibited nonlinearities of the medical robotic system that affects the system's performance. Moreover, they may cause a serious challenge for designing a suitable controller to reach the optimal response for different affections.

Practically, the motivation of studying the motion mechanism of the medical robot system is for different reasons such as moving in uneven ground, risky jobs, or environments with choppy supports like a ladder, also in restoring motion for the disabled [2]. Healthy stalks are important for humans to perform daily life activities such as seated, walk and run, from all these activities and more, walking is considered as the most important, which is characterized by particularly nonlinear dynamics and can be represented as a pendulum link as well as the swing leg system [3]. And for its importance for medical and health care applications, it has been considered recently as an active field of study; plenty of research works done to effectively control this type of system 
with various interesting approaches. Starting with [3, 4] where they presented a trajectory tracking control method with feedback linearization controller of fixed and movable double pendulums for a joint selfimpact model of the swing leg for a human. They gained an accepted error of normal ways of walking. In [5], the authors designed three degrees of freedom robotic leg with analysis of 2D plane motion and joints angle orientation. The results show considerably accepted average error for hip, knee, and ankle respectively. In [6], a fast gait-modedetection method has been proposed. It shows the effectiveness of the gait-mode-based assistive strategy depending on using electromyography muscular activities.

The authors in [7-10], showed a robustly stabilize of the nonlinear pendulum links, hip, and knee of the human swing leg system. The desired response specifications have been obtained using the sliding mode control (SMC) robustness properties [7], fullstate feedback H-infinity controller [8], dynamic output feedback by combining both $\mathrm{H}_{2}$ state feedback and PID controllers with the cultural algorithm (CA) method as an effective optimization algorithm [9], and the H-infinity Sliding Mode Control (HSMC) by combining both of the H-infinity and SMC controllers robustness that considered as complex intelligent controller [10]. The applied controllers in [7-10] shows robust effective stabilization for the system and achieve better specifications of time response than those with applying either only $\mathrm{H}$ infinity or SMC controllers.

Another work by [11] had implemented $\mathrm{H}_{\infty}$ loopshaping as a robust controller. It resulted in better performance as compared to both PID and SMC controllers on the swing leg robotic system. Meanwhile, [12] presented 2nd order arm robot dynamic system with the classic Recursive NewtonEuler (RNEA) method. The authors used a feedback linearization method for motion control, which behaves equitable effectiveness for trajectory tracking of the system-based control.

In [13] the author designed a tracking controller to achieved position and stiffness of the variable stiffness joint. While in [14] the authors presented comparative effectiveness of both Genetic Algorithm-Back propagation neural network and a repeated event-triggered SMC sketch for lower limb human-robot for both simulation and experimental analysis.

A mechanism called COWALK-Mobile 2 presented in [15] showed that larger joints of both hip and knee torques were generated with smaller actuator torques as compared with a healthy walking human on a level surface. While [16] presented 3DoF robotic arm motion controlled by of Fuzzy cascade controller tuned by Genetic algorithm-simple additive weighting (GA-SAW) compared with a conventional PID controller, which shows an undesirable transient response of both the settling time and rise time. Also, in [17], the design of an adaptive type- 2 fuzzy backstepping controller is presented, where the convergence speed of the control algorithm has been improved, and its steadystate error has been reduced for the robot manipulator. While [18] introduces three types of techniques for tuning the robot manipulator, which are PID, Sliding Mode Control SMC, and Integral Sliding Mode Control (ISMC) using Intelligent Particle Swarm Optimization (PSO) to achieve the optimum controllers' parameters. Results show that ISMC with PSO had the best result for stable step response.

Eventually, PID control is a known multivariable lower-level control element that has been used with many technology transformations, such as mechanical systems to microprocessors. PID controllers provide robust and reliable performance for most systems if the PID parameters are tuned properly. Many types of PID controllers are considered nowadays in industrial applications for their improved performance such as using some intelligent ways for tunning the PID controller parameters [6-8], two degrees of freedom PID (2DoFPID) [19], and nonlinear PID (NPID) [20].

The main drawback that has been noticed in controlling the multivariable medical robot system is not considering the effects of interaction between the inputs and outputs.

Relative gain array is a widely used technique for the design of multivariable control systems. It is usually used to measure loop interaction in multivariable control system design.

Consequently, the motivation of this paper is to design a suitable multivariable interactive controller for the medical robot system with the consideration of the interaction problem using the RGA evaluation. Accordingly, the main contributions of the proposed control method are as follows:

1- The effects of the systems' inputs and outputs interaction is considered and compensated for by calculating the RGA for different types of PID controllers. to reach the desired joint position degree.

2- The implementation of an intelligent approach like Fuzzy logic control algorithm for tuning the PID controller parameters to improve the system's response.

3- Comparison with other non-standard types of PID controllers, as 2DoFPID and NPID controllers.

4- Robustness of the developed controlled system is investigated by considering the presence of 
disturbances and measurement noise in the model of the system. In addition, the robustness of the controlled system is also investigated by considering uncertainties with the model of the system.

Moreover, the results show that although (NPID) and 2DoFPID can provide acceptable performance, their application and tuning have some difficulties; although the NPID is more sensitive to the tuning of the controller's parameters. The 2DoFPID results in a highly disturbed control signal with a high overshoot in the resulted response.

The remaining of the paper will be structured as follows: many related works; the mathematical model of the medical robot system is presented in Section 2; Section 3 describes the interaction and RGA calculations. Section 4, has introduces the theoretical concepts of both the PID and Fuzzy PID controllers with proposing the interaction effects depending on the RGA calculations for both controllers. In Section 5, we present other types of PID controller. The proposed controllers' measuring performance is presented in Section 6. While in Section 7. the simulation implementation with a comparison of controllers' responses are presented with robustness test for both systems' disturbance and uncertainty. Finally, conclusions are given in Section 8 .

\section{System description and mathematical modeling}

To represent the mathematical model of medical robot leg, the physics complications of the robot leg must be considered. The medical robot is represented by two links which are thighed in movement by each other, the first link that connected the basin with the knee effects the second link motion that connected the knee to the foreleg. Theoretically, the knee angle may have any value which is insensible to the value of hip rotation angle, where, for human legs, this assumption is not valid, and the shank cannot assume the rotation angles which are greater than that of the thigh.

However, the simplified medical robot system model may be considered as a double pendulum system where the unconstrained dynamic equation written as in Eq. (1), can be accomplished by accounting for the motion of the hip and knee with neglecting the ankle motion defined as $[7,11]$ :

$$
M(\theta) \ddot{\theta}+C(\theta, \dot{\theta}) \dot{\theta}+G_{t}(\theta)=\tau
$$

where $\theta, \dot{\theta}, \ddot{\theta}$ are $2 \times 1$ vectors of joint angles, joint angular velocities, and joint angular accelerations, respectively; $M(\theta)$ is $2 \times 2$ symmetric positive

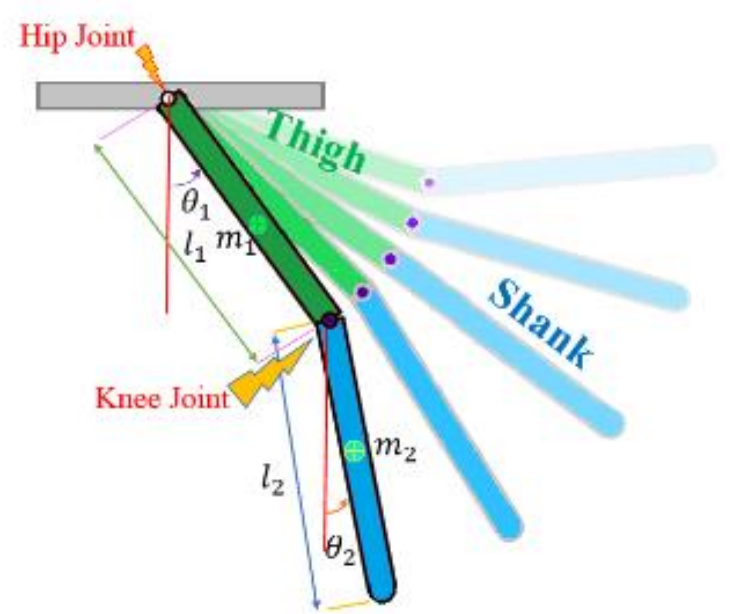

Figure. 1 Schematics of an unconstrained medical robot system $[7,11]$

definite inertia matrix; $C(\theta, \dot{\theta})$ is $2 \times 1$ vector of Coriolis; $G_{t}(\theta)$ is $2 \times 1$ vector of gravitational torques and $\tau$ is $2 \times 1$ vector of actuator joint torques, where these matrix's depented on the robot specifications such as $m_{1}$ and $m_{2}$ are the thigh and shank masses, and they are $0.1 \mathrm{Kg}$, while $l_{1}$ and $l_{2}$ are thigh and shank lengths, respectively, and they equal to $0.55 \mathrm{~m}$. $\theta_{1}$ and $\theta_{2}$ denoted the rotation angles of the hip and knee with respect to the perpendicular axis, $\tau_{1}$ and $\tau_{2}$ are the external torques that applied move the thigh and shank links, and $\mathrm{g}$ is gravitational and it's 9.81 $\mathrm{m} / \mathrm{s}^{2}$. Fig. 1 shows a schematic of an unconstrained medical robot system.

The representation for the resulting system in state space is:

$$
\begin{aligned}
& \dot{x}(t)=A x(t)+B u(t) \\
& y(t)=C x(t)+D u(t)
\end{aligned}
$$

where:

$$
\begin{gathered}
A \\
=\left[\begin{array}{cccc}
0 & 0 & 1 & 0 \\
0 & 0 & 0 & 1 \\
-19.8873 & 3.8075 & -0.2155 & -0.2039 \\
18.5281 & -22.2111 & 0.6116 & 0.2874
\end{array}\right] \\
B=\left[\begin{array}{cc}
0 & 0 \\
0 & 0 \\
49.2616 & -69.4362 \\
-69.4362 & 197.0466
\end{array}\right] \\
C=\left[\begin{array}{cccc}
1 & 0 & 0 & 0 \\
0 & 1 & 0 & 0
\end{array}\right], D=\left[\begin{array}{ll}
0 & 0 \\
0 & 0
\end{array}\right]
\end{gathered}
$$

The open-loop simulation response of both medical robotic system joints shows a high instability, as shown in Fig. 2, where a need for a suitable 


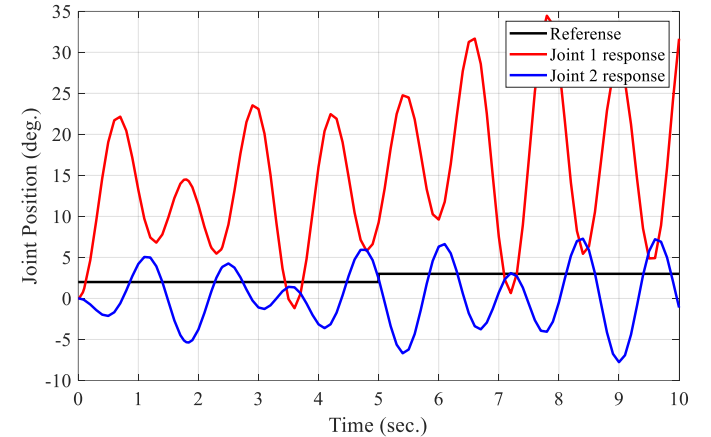

Figure. 2 Open loop medical robot system response

controller to improve the system's performance and stability.

\section{Interaction and relative gain array (RGA) calculations}

RGA is utilized to find the best pairing that corresponds to good controller performance. After applying RGA calculations to develop the required controllers. The interaction can be described with equations below [21] and illustrated in Fig. (3)

$$
\begin{aligned}
& \Delta u_{1}=g_{11} \Delta e_{11}+g_{12} \Delta e_{12} \\
& \Delta u_{2}=g_{21} \Delta e_{21}+g_{22} \Delta e_{22}
\end{aligned}
$$

where $\Delta u_{1}$ and $\Delta u_{2}$ represent the control signal for first and second joints respectively, $\Delta e_{i j}$ represent the errors' signal between input $i$ and output $j$, and $g_{i j}$ represent the prosses gain between input $i$ and output $j$, e.g. $g_{11}$ can be defined by

$$
g_{11}=\frac{\left(\frac{\Delta u_{1}}{\Delta e_{11}}\right)_{\Delta e_{12}=0}}{\left(\frac{\Delta u_{1}}{\Delta e_{11}}\right)_{\Delta u_{2}=0}}
$$

The RGA had been introduced by Bristol as a tool for pairing controlled and manipulated variables in decentralized control system. It is a useful tool in proving the pairing selection between inputs and outputs for diametrical control design, as shown in Fig. 3, where the main idea of it is to estimate the election of each output on a specific open-loop variable of the controller. For a $2 \times 2$ matrix with elements $g_{i j}$, the RGA is represented as in the following equation:

$$
R G A=\left[\begin{array}{ll}
g_{11} & g_{12} \\
g_{21} & g_{22}
\end{array}\right]
$$

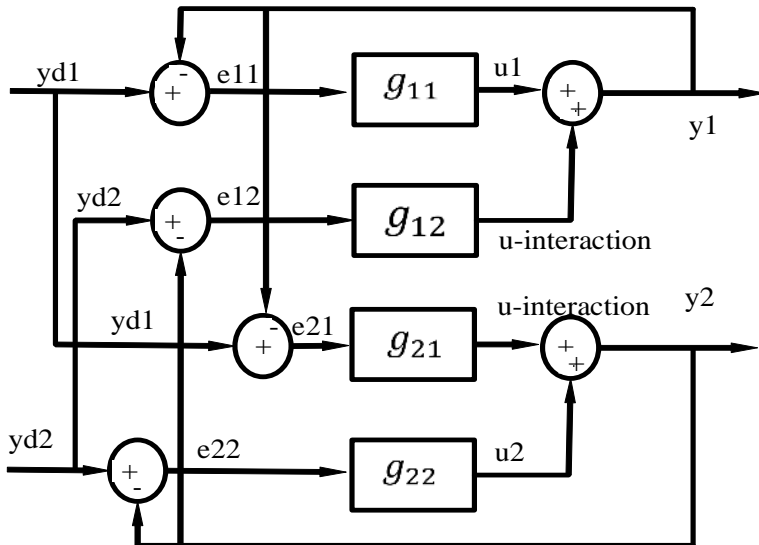

Figure. 3 Fully decoupled controller of medical robot system

As long as the RGA is square so that every row and every column sum is 1 ; so after substituting $g_{12}=$ $g_{21}=1-g_{11}$ and $g_{11}=g_{22}$. The relative gains are dimensionless, and no matter for used units for process gains, on condition that they are consistent, the RGA will be as the following:

$$
R G A=\left[\begin{array}{cc}
g_{11} & 1-g_{11} \\
1-g_{11} & g_{11}
\end{array}\right]
$$

From Eq. (8), if the process gain has a positive value in the diagonal this indicate that the interaction reduces the effect gain of the control loop. Higher controller gains are required; in another hand if the process gain has a negative off-diagonal element indicates that closing the loop will change the sign of effective gain. While it indicates to have an interaction between the control loops for process gain value between the conditions mentioned above.

Furthermore, linear behavior analysis was assumed. The changing of the operating conditions is probably the same as varying the process gains.

Consequently, the RGA recalculating under these conditions may modify the deductions in terms of both pairing and decoupling. For the reasons mentioned above, the RGA may only be considered as a technique for eliminating some of the pairing options and suggesting configurations that need to be evaluated further.

\section{Interactive PID controller design based on RGA calculations for medical robot system}

The PID (proportional-integral-derivative) controller is the most common and simple form of feedback. This makes it suitable to be implemented with RGA calculations, as well as applying the Fuzzy logic for tuning the PID controller parameters to 


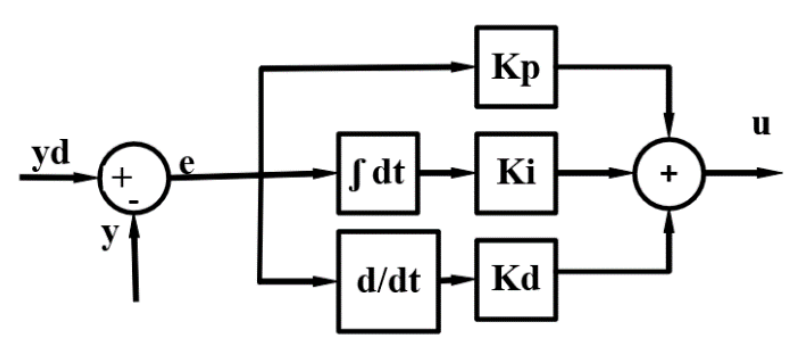

Figure. 4 Classical PID controller

reach a simple controller with high performances responses for the system.

\subsection{Conventional PID controller}

The conventional PID controller has advantages of structure simplicity, high robustness, the wide design process used in the simulated systems, and the efficacy and reliability, and besides the required accurate adjustment of its parameters, it also depended on the system's parameters to reach the desired performances [21]. It has been applied here to the medical robotic, as shown in Fig. 4. The output or control effort of a proportional (P) integral (I) and derivative (D) control algorithm is given, in general, by the following equation;

$$
u(s)=K_{p} e(s)+K_{i} \frac{1}{s} e(s)+K_{d} s e(s)
$$

where the $K_{p}$ is the proportional gain, $K_{i}$ the integral gain, $K_{d}$ is the derivative gain, $e$ is the error and $u$ is the control signal.

\subsection{Fuzzy logic PID controller}

Fuzzy PID controllers are applied modern control system applications [22]. Fig. 5 shows the three main fuzzy structure parts, in Mamdani type which are: fuzzification, inference, and defuzzification. Fuzzy control algorithm work has been developed for tunning the PID controller parameters after verifying the rules of fuzzy control, membership functions, scaling factors, and defuzzification strategy with several trials where the inputs, e and de/dt are normalized using membership functions.

A parallel connection between the fuzzy module and PID parameters as shown in Fig. 6, where the fuzzy logic controller is tuning the parameters to reach the required performance [22] and the PID structure remains unchanged in spite of the presence of Fuzzy controller, which enables the application of RGA.

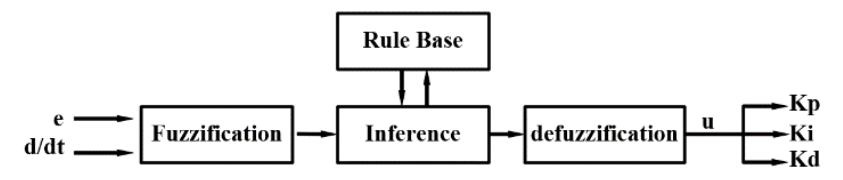

Figure. 5 Fuzzy controller structure

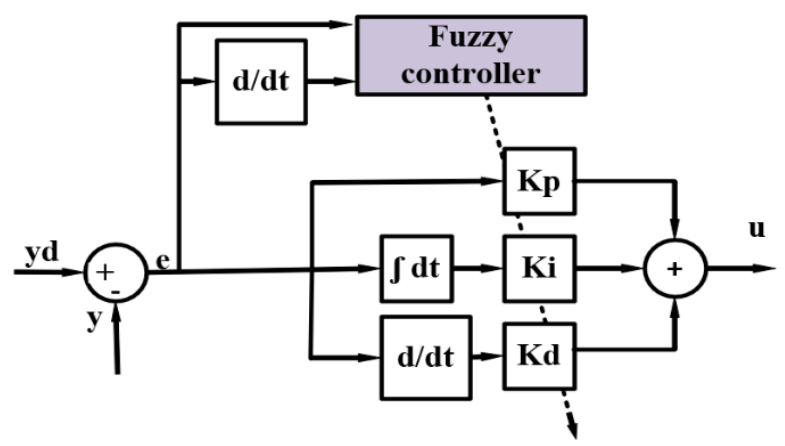

Figure. 6 Self tunning Fuzzy PID controller

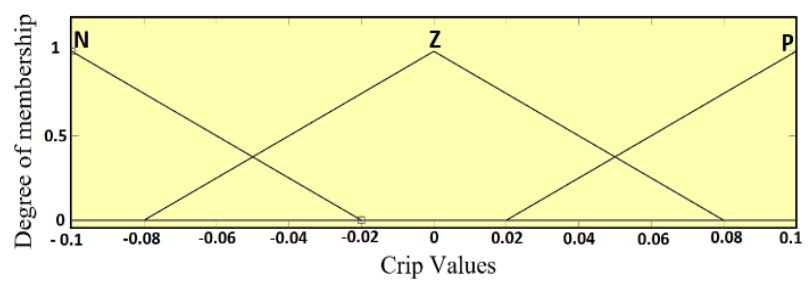

(a)

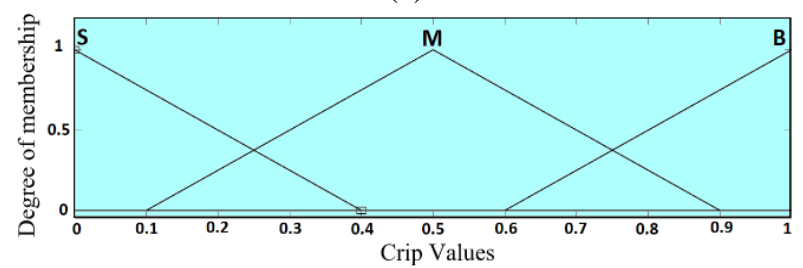

(b)

Figure. 7 Membership variable function for: a) Both inputs e and de/ dt. b) All outputs $K_{p}, K_{i}$, and $K_{d}$

Table 1. The rule base of Fuzzy

\begin{tabular}{|c|c|c|c|c|c|c|c|c|c|}
\hline & \multicolumn{3}{|c|}{$\mathbf{N}$} & \multicolumn{3}{|c|}{$\mathbf{Z}$} & \multicolumn{3}{|c|}{$\mathbf{P}$} \\
\hline & $K_{p}$ & $K_{i}$ & $K_{d}$ & $K_{p}$ & $K_{i}$ & $K_{d}$ & $K_{p}$ & $K_{i}$ & $K_{d}$ \\
\hline $\mathbf{N}$ & $S$ & S & $\mathrm{S}$ & $\mathrm{S}$ & $\mathrm{S}$ & $S$ & $S$ & $\mathrm{~S}$ & $\mathrm{~S}$ \\
\hline $\mathbf{Z}$ & $\mathrm{M}$ & $\mathrm{M}$ & $\mathrm{M}$ & $\mathrm{M}$ & $\mathrm{M}$ & $\mathrm{M}$ & $\mathrm{M}$ & $\mathrm{M}$ & $\mathrm{M}$ \\
\hline $\mathbf{P}$ & B & B & B & B & B & B & B & B & B \\
\hline
\end{tabular}

In this paper the following membership functions as show in figure (7-a) and figure (7-b) respectively; negative $\mathrm{N}$, zero $\mathrm{Z}$, positive $\mathrm{P}$, so that the rules base as illustrated in Table 1.

\section{Comparisons with non-conventional PID controllers}

In order to justify the applied approach, two other types of PID controllers have been implemented; the NPID and 2DPID. Which can be considered efficient robust PID controllers [19]. However, the interactive control approach cannot be applied; because of their 


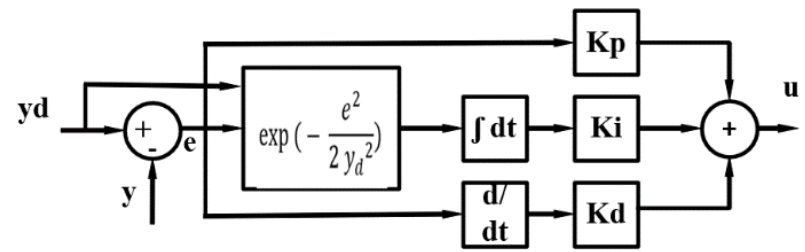

Figure. 8 The implemented NPID controller

nonlinear structures that are more complicated and have bad effects on the feasibility and robustness of the controlled system so it is difficult to use the RGA calculations with these types of controllers. The detailed description will be presented in the following:

\subsection{Nonlinear PID controller}

Nonlinear PID (NPID) controller depended on simplified proportional, and differential gains with nonlinear integral gain, that can be changed according to the error control signal [20]. Quickness, high accuracy, and no overshoot are considered as advantages of the NPID. The integral action contains a nonlinear function while the other ( $\mathrm{P}$ and $\mathrm{D})$ actions are linear. Hence, the error input to the integral action is scaled by a nonlinear function in the form of the product of the error and a nonlinear gain. Figure.8, shows the NPID controller block diagram. To evaluate all the control system performance integration of continuous time-weighted absolute error is applied, as in Eq. (10) [23]:

$$
u(s)=K_{p} e(s)+\frac{1}{s} e^{-\left(\frac{e(s)^{2}}{2 y_{d}^{2}}\right)} e(s)+K_{d} s e(s)
$$

where the addition to the classical PID controller is represented by the exponential nonlinear function which provides a nonlinearity measured error as stated by $e$, and $y d$ as the desired response.

\subsection{Two-Degree-of-Freedom PID controller (2DoFPID)}

One of the interested applications of the PID controllers is the two-degree-of-freedom (2DoF) for its considerations the control performance regulatory with the robustness of the close loop system to upgrade the servo-control behavior. The features of 2DoF depended on the combination of both PI and PID control algorithms [19]. The 2DoF PID control algorithm is given by the following equation:

$$
u(s)=K_{p}\left\{\beta y_{d}+\frac{1}{T_{i} s} e(s)+\frac{T_{d} s}{\alpha T_{d} s+1} e(s)\right\}
$$

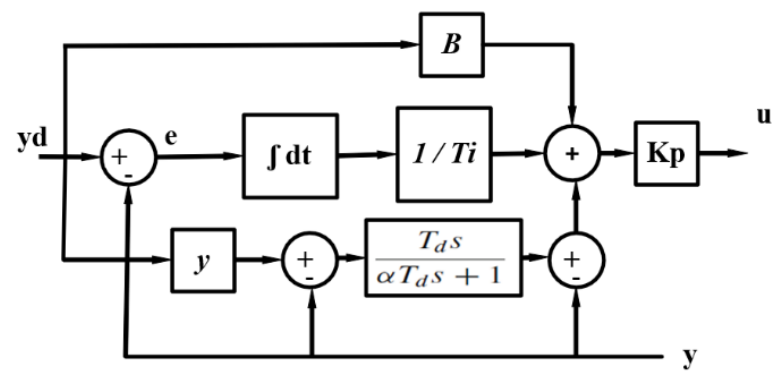

Figure. 9 Two degree of freedom of PID controller

where $K_{p}$ is the main proportional controller gain, $\beta$ and $\gamma$ are the set-point weights, $T_{i}$ is the integral time constant, $T_{d}$ is the derivative time constant, and $\alpha$ is the derivative filter constant, as shown in Fig. 9. As it can be clearly noticed, the structure is more complicated than a conventional PID, RGA cannot be applied.

\section{Performance measure of the robot controlled system}

As can be seen from Eqs. (1) to (3), the models are quite standard approximations because of the system coupling of both inputs and outputs, this will tremendously increase the nonlinearity of the system and decrease performance quality.

Since it is required to improve the stability and performance of the medical robot system. Reasonable performance specifications need to be priory specified to test the effect of the previously mentioned controllers.

There are various system performance measures which can be used to measure the performance of the applied controller. The selected performance measure will be utilized for the comparison between the applied types of PID controllers. In this paper, the Integral Square Error is used, as in the following equation below [23]:

$$
I S E=\int_{0}^{\infty}[e(t)]^{2} d t
$$

where $e(t)$ is a measure value of error at time $t$.

\section{Simulation results}

The simulation has been constructed using the medical robot system as described in Section 2. The previously described controllers in Sections 4 and 5 have been applied and tested as will be illustrated. The simulations experiments have been conducted using MATLAB/Simulink. 


\subsection{Interactive PID and Fuzzy PID controllers}

The first step is evaluating the RGA for the robotic system described by Eqs. (2) and (3) in order to find the coupling status of the robotic system. It has been found that the major coupling is between input 1 and output 2. And according to the related property of RGA, there is an interaction between the control loops, therefore it would be better to minimize the interaction by introducing a suitable controller between these interacting variables. Meanwhile, the interaction between input 2 and output 1 has less effect of interaction. Consequently, PID controllers have been designed for each pairing of the controlled system.

Fig. 10 and 11 present the joints position responses of the closed loop tracking controlled system using the proposed interactive PID and interactive Fuzzy PID controllers compared with ordinary PID and Fuzzy PID controlled systems. Fig. 12 and 13 present the corresponding controllers' actions. From the results shown in figures and the transient response analysis, it's clear that the performance has noticeable improvement for both PID and Fuzzy PID controllers after considering the interaction effects, as shown in the results of Table 2,

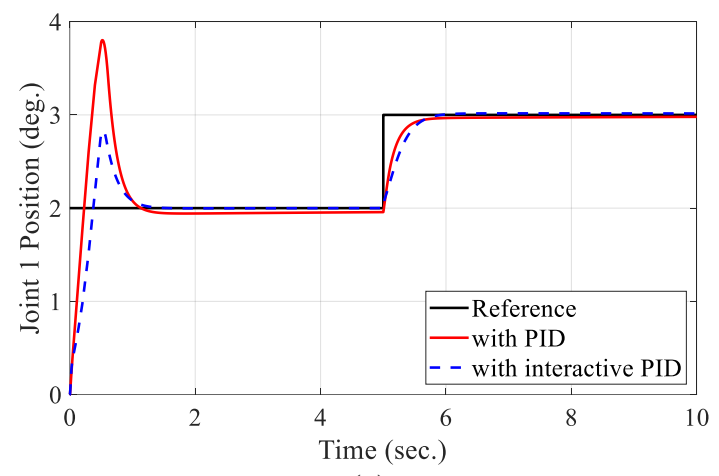

(a)

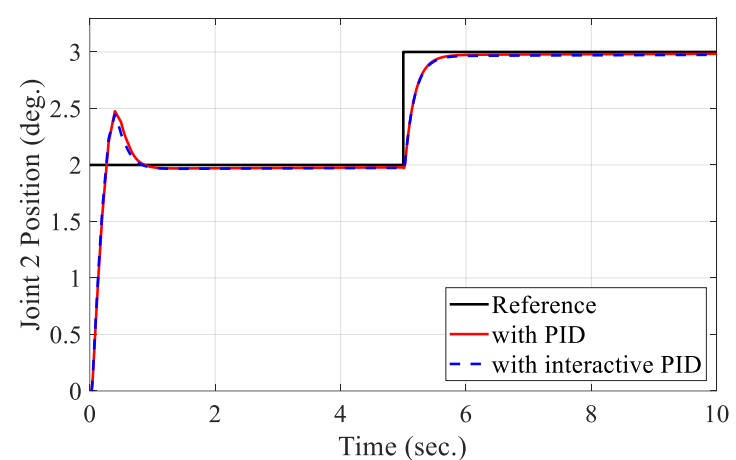

(b)

Figure. 10 Response of the medical robotic system under PID controller with and without the interaction effects for

(a) $1^{\text {st }}$ joint position and (b) $2^{\text {nd }}$ joint position

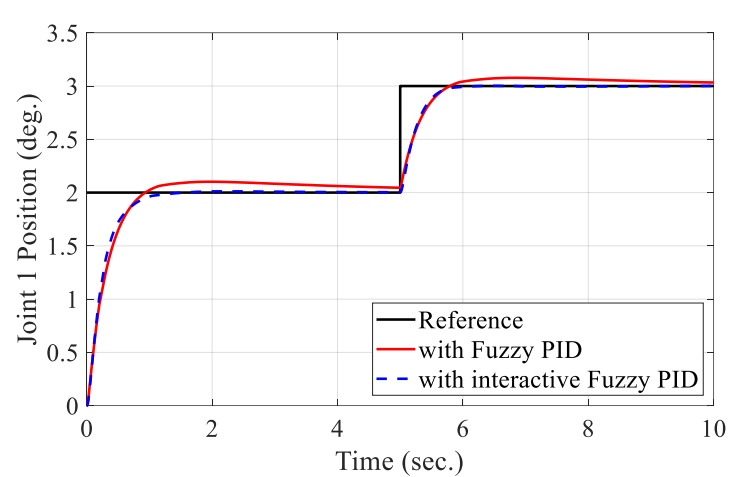

(a)

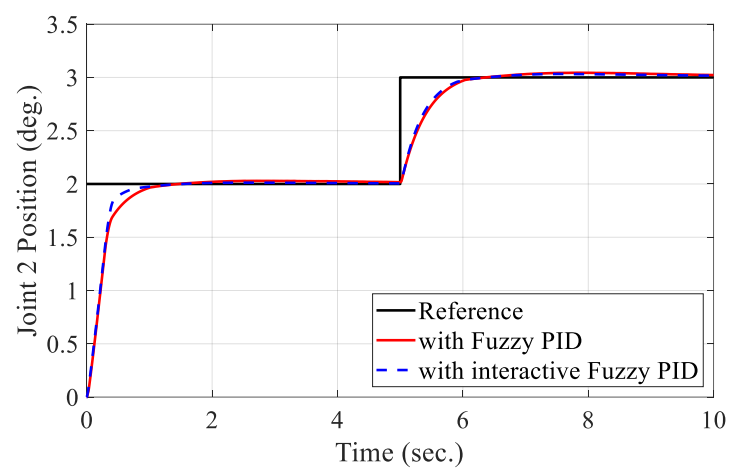

(b)

Figure. 11 Response of the medical robotic system under Fuzzy PID controller with and without the interaction effects for (a) $1^{\text {st }}$ joint position and (b) $2^{\text {nd }}$ joint position

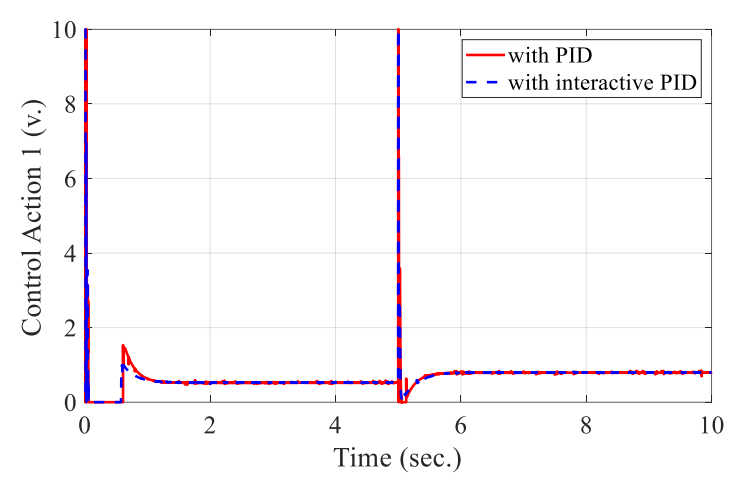

(a)

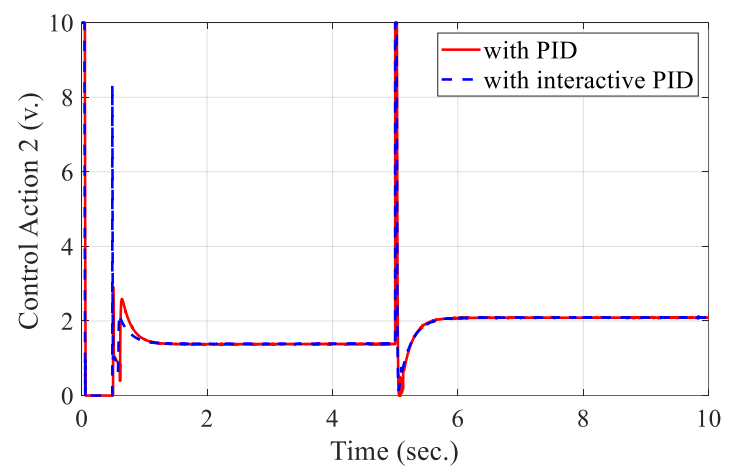

(b)

Figure. 12 Control action using the PID controller before and after adding the interaction effects for (a) $1^{\text {st }}$ medical robot joint position and (b) $2^{\text {nd }}$ medical robot joint position 


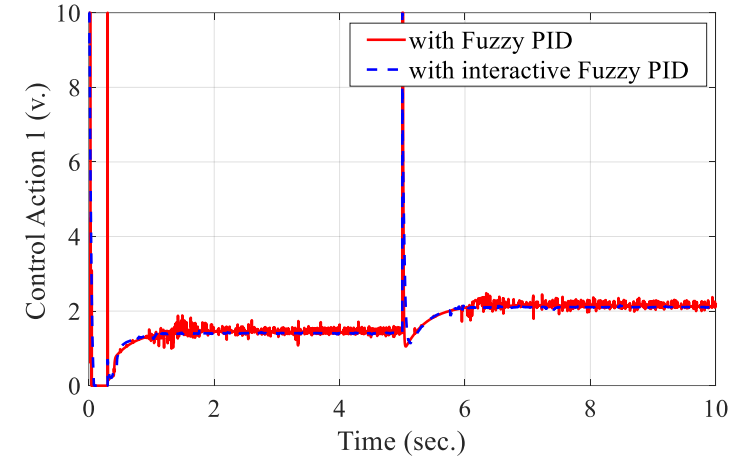

(a)

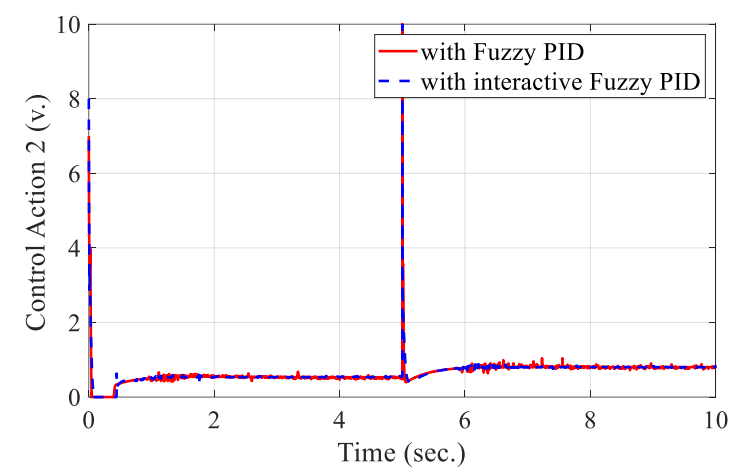

(b)

Figure. 13 Control action using the Fuzzy PID controller before and after adding the interaction effects for (a) 1 st medical robot joint position and (b) 2nd medical robot joint position

Table 2. The PID controllers type Performance

\begin{tabular}{|c|c|c|c|c|c|c|}
\hline 离 & 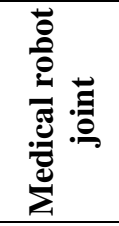 & 导 & 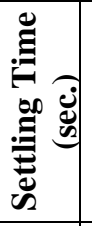 & 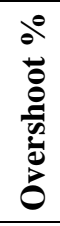 & 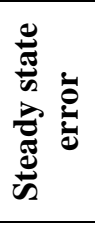 & 岳 \\
\hline \multirow{2}{*}{ 是 } & $1^{\text {st Joint }}$ & $\begin{array}{c}0.08 \\
1 \\
\end{array}$ & 1.5 & 1.8 & $\begin{array}{c}0.04 \\
5 \\
\end{array}$ & $\begin{array}{c}52.18 \\
7 \\
\end{array}$ \\
\hline & $\begin{array}{c}2^{\text {nd }} \text { Join } \\
t\end{array}$ & $\begin{array}{c}0.08 \\
8\end{array}$ & 1.3 & 0.5 & $\begin{array}{c}0.03 \\
5\end{array}$ & $\begin{array}{c}50.02 \\
4\end{array}$ \\
\hline \multirow{2}{*}{ 竞 } & $1^{\text {st Joint }}$ & $\begin{array}{c}0.17 \\
0 \\
\end{array}$ & 1.2 & $\begin{array}{c}0.8 \\
2 \\
\end{array}$ & $\begin{array}{c}0.01 \\
7 \\
\end{array}$ & $\begin{array}{c}38.30 \\
6 \\
\end{array}$ \\
\hline & $\begin{array}{c}2^{\text {nd }} \text { Join } \\
\mathrm{t}\end{array}$ & $\begin{array}{c}0.07 \\
8\end{array}$ & 1.2 & $\begin{array}{c}0.4 \\
2\end{array}$ & $\begin{array}{c}0.03 \\
7\end{array}$ & $\begin{array}{c}36.35 \\
2\end{array}$ \\
\hline \multirow{2}{*}{$\underset{2}{a}$} & $1^{\text {st Joint }}$ & $\begin{array}{c}0.18 \\
7 \\
\end{array}$ & $\begin{array}{c}1.1 \\
5 \\
\end{array}$ & $\begin{array}{c}1.0 \\
2 \\
\end{array}$ & 0.02 & $\begin{array}{c}28.43 \\
2 \\
\end{array}$ \\
\hline & $\begin{array}{c}2^{\text {nd }} \text { Join } \\
\mathrm{t}\end{array}$ & $\begin{array}{c}0.17 \\
1\end{array}$ & 1.3 & --- & $\begin{array}{c}0.02 \\
4\end{array}$ & $\begin{array}{c}28.53 \\
9\end{array}$ \\
\hline \multirow{2}{*}{ 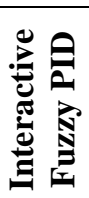 } & $1^{\text {st Joint }}$ & $\begin{array}{c}0.13 \\
9 \\
\end{array}$ & $\begin{array}{c}0.9 \\
7 \\
\end{array}$ & --- & $\begin{array}{c}0.00 \\
1 \\
\end{array}$ & $\begin{array}{c}28.26 \\
8 \\
\end{array}$ \\
\hline & $\begin{array}{c}2^{\text {nd }} \text { Join } \\
\mathrm{t}\end{array}$ & $\begin{array}{c}0.16 \\
4\end{array}$ & $\begin{array}{c}0.8 \\
5\end{array}$ & - & $\begin{array}{c}0.01 \\
7\end{array}$ & $\begin{array}{c}28.54 \\
5\end{array}$ \\
\hline
\end{tabular}

where simulation results show an improvement of about $44 \%$ for the Fuzzy PID controller as compared with the conventional PID controller. On the other hand, the comparison shows a 70\% improvement in steady state error after considering the interaction effects.

\subsection{Nonlinear PID and Two-Degree-of-Freedom PID (2DoFPID) Controllers}

The medical robot responses, as shown in Fig. 14 and 15 , for both 1 st and 2 nd joints position and control signal for the NPID controller, where it is clear that the controller's response in tracking the desired signal with the unexpectable transient response and having a smaller steady-state error. Also, the performance of the system with NPID controller suffers from a relatively higher sensitivity to parameter variations.

While, Fig. 16(a) and 16(b), show the 2DoFPID controller joints position for both automatic and manually tunning types respectively, which obviously have undesired overshoot also higher stelling time for the controller manually tuned as compared with the auto. controller response and Fig. 17(a), and Fig. 17(b), shows the 2DoFPID controller control signal for both automatic and manually tunning types respectively, that shows very high chattering to be implemented with the system.

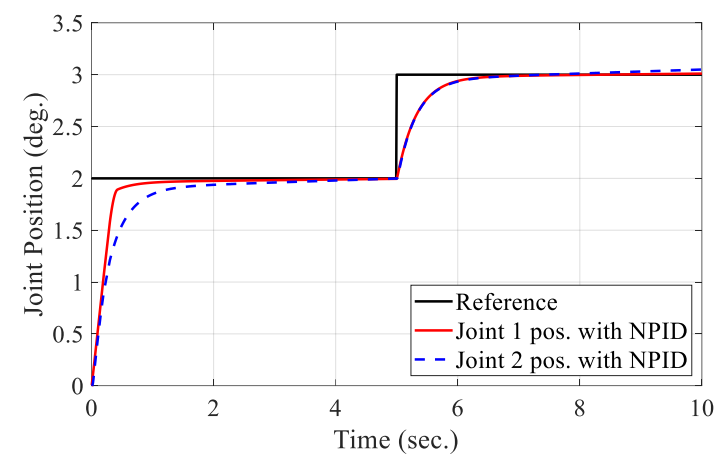

Figure. 14 NPID controller response for both $1^{\text {st }}$ and $2^{\text {nd }}$ medical robot joints position

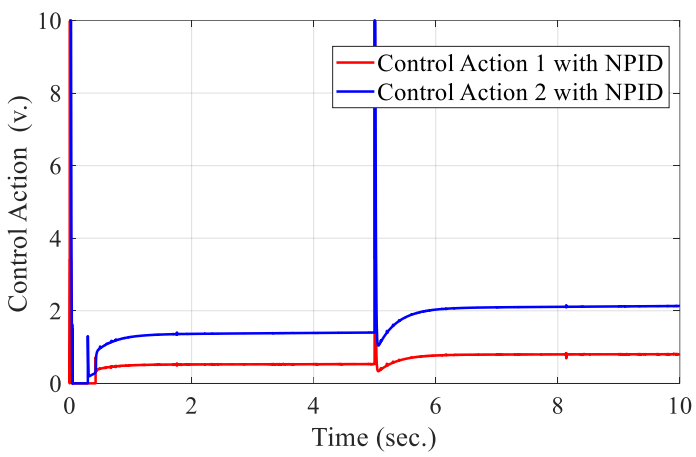

Figure. 15 NPID control action response for both $1^{\text {st }}$ and $2^{\text {nd }}$ medical robot joints position 


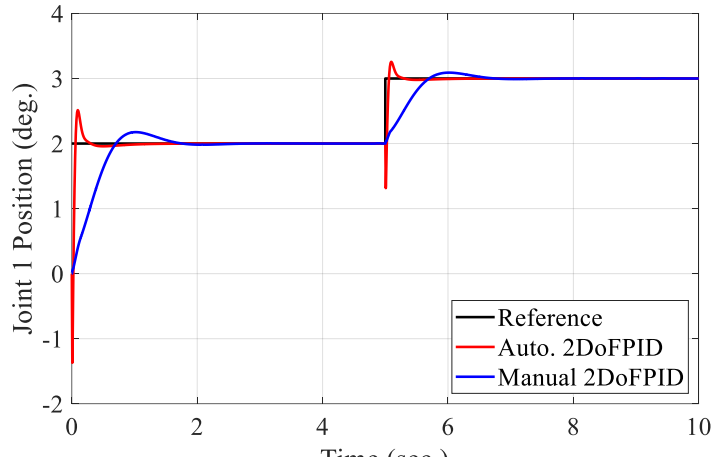

(a)

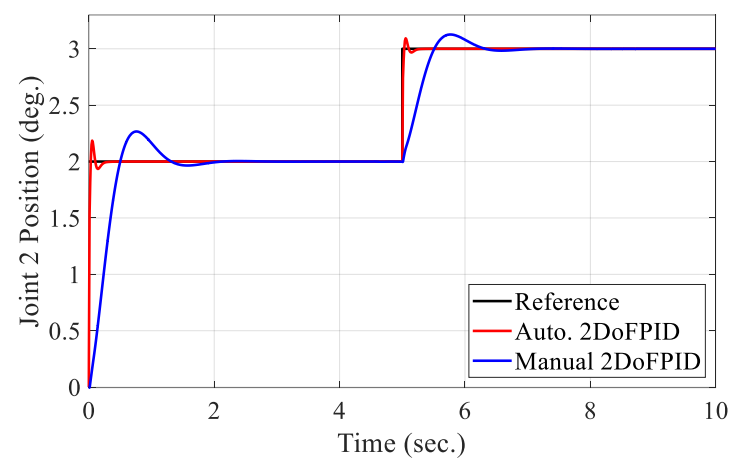

(b)

Figure. 16 Two types 2DoFPID controllers response for: (a) $1^{\text {st }}$ medical robot joints position and (b) $2^{\text {nd }}$ medical robot joints position

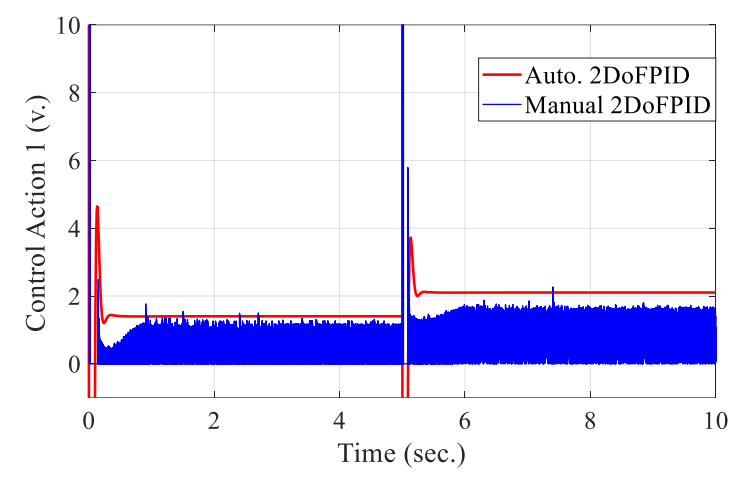

(a)

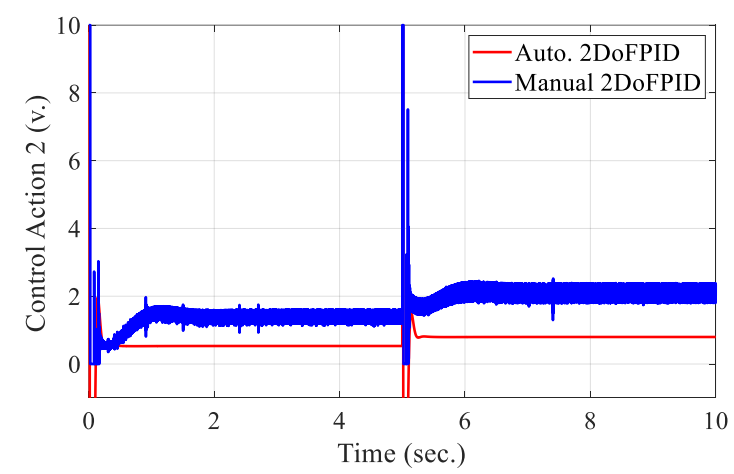

(b)

Figure. 17 2DoFPID control action (a) $1^{\text {st }}$ medical robot joints position and (b) $2^{\text {nd }}$ medical robot joints position
Table 3. The PID controllers type Performance comparison

\begin{tabular}{|c|c|c|c|c|c|c|}
\hline 㐫 & 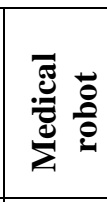 & 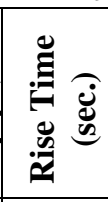 & 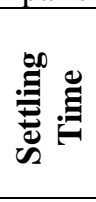 & 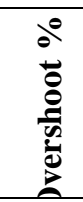 & 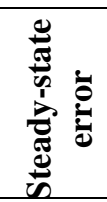 & 牙 \\
\hline \multirow{2}{*}{ 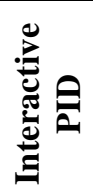 } & $\begin{array}{c}1^{\text {st }} \text { Join } \\
t\end{array}$ & 0.170 & 1.2 & 0.82 & 0.017 & 38.306 \\
\hline & $\begin{array}{c}2^{\text {nd }} J_{o i} \\
n t\end{array}$ & 0.078 & 1.2 & 0.42 & 0.037 & 36.352 \\
\hline \multirow{2}{*}{ 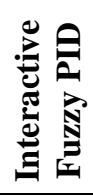 } & $\begin{array}{c}\text { 1 }^{\text {st Join }} \\
\mathrm{t}\end{array}$ & 0.139 & 0.97 & --- & 0.001 & 28.268 \\
\hline & $\begin{array}{c}2^{\text {nd }} \mathbf{J o i} \\
\mathrm{nt}\end{array}$ & 0.164 & 0.85 & --- & 0.017 & 28.545 \\
\hline \multirow{2}{*}{$\frac{\hat{2}}{\bar{z}}$} & $\begin{array}{c}1^{\text {st Join }} \\
t\end{array}$ & 0.162 & 1.4 & --- & 0.04 & $\begin{array}{c}3.062 \mathrm{e} \\
+3\end{array}$ \\
\hline & \begin{tabular}{|c}
$2^{\text {nd }}$ Joi \\
$n t$
\end{tabular} & 0.148 & 3.5 & --- & 0.02 & \begin{tabular}{|c}
$3.015 \mathrm{e}$ \\
+3 \\
\end{tabular} \\
\hline \multirow{2}{*}{ 产 } & $\begin{array}{c}1^{\text {st Join }} \\
\mathrm{t}\end{array}$ & 0.011 & 1 & 1.26 & 0.003 & $\begin{array}{c}2.501 \mathrm{e} \\
+3\end{array}$ \\
\hline & $\begin{array}{c}2^{\text {nd }} \text { Joi } \\
n t\end{array}$ & 0.004 & 0.4 & 1.09 & 0.003 & $\begin{array}{c}2.497 \mathrm{e} \\
+3\end{array}$ \\
\hline
\end{tabular}

\subsection{Comparison of the PID controllers}

Table 3 illustrate a summary of the transient behavior for the systems after applying the previously described types of PID controllers. It can be noticed that response suffers high percentage overshoot and oscillatory behavior with PID and 2DoFPID controllers. Using the Fuzzy logic controller for tunning PID parameters structure helps to reduce the percentage overshot considerably. Nevertheless, the settling time has decreased reaching its lowest time with interaction Fuzzy PID controller. Obvious improvements can be seen in the transient behavior as well as the robustness against uncertainty. Considerable improvements have been gained in the steady-state error values of the proposed controllers. It is clear that the proposed interactive Fuzzy PID control structure can robustly stabilize the medical robot controlled systems.

\subsection{Robustness analysis in presence of Disturbance and Nosie}

Meanwhile, in order to analyze the robust performance of the controlled systems, the input signal is subjected to a small input disturbance of $+50 \%$ and $-20 \%$ of reference input value with the addition of measurement noise of $\pm 2 \%$ all the simulation time. The PID controllers designed alleviate the effects of both input disturbances and noise then stabilizes the close loop system. As shown in Fig. 18(a) and 18(b) for both $1^{\text {st }}$ and $2^{\text {nd }}$ joints 


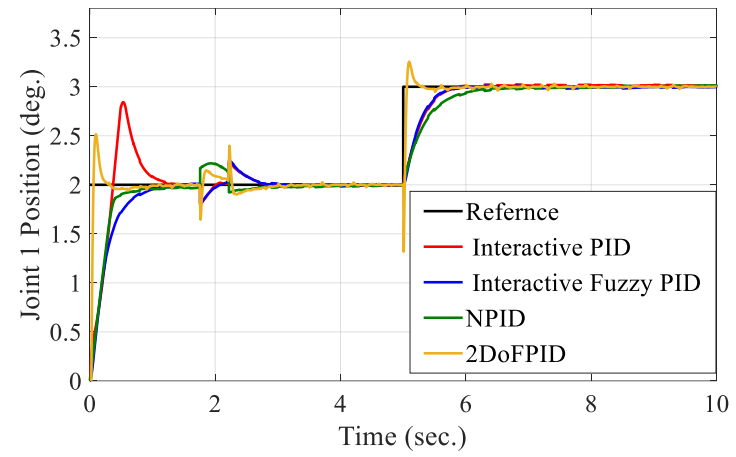

(a)

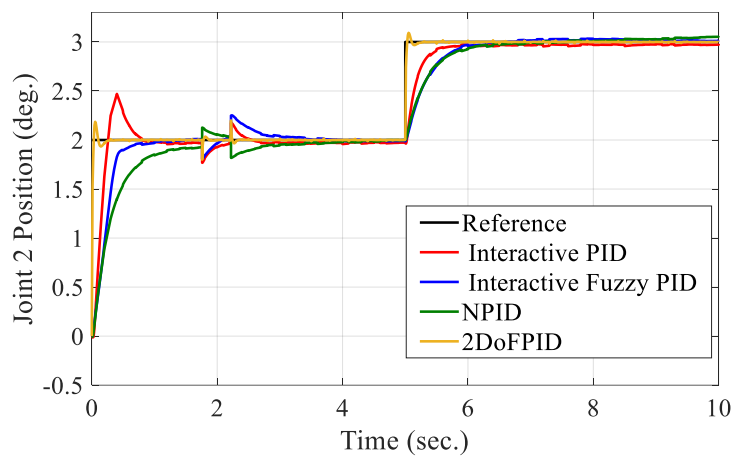

(b)

Figure. 18 The PID controllers type response for the medical robot: a) $1^{\text {st }}$ joint with the addition of disturbance and measurement noise. b) $2^{\text {nd }}$ joint with the addition of disturbance and measurement noise

position response, a comparison between the applied types of PID controllers shows the close loop response for each type and the ways to over gates the outside effects also to demonstrate the effectiveness of the applied approaches listed in Table 4.

It is clearly noticed from these graphs that the proposed PID controller types especially interactive Fuzzy PID controller in Fig. 18(a) and 18(b) can maintain better tracking performance as compared with the other controllers' types, even in the presence of both disturbance and noise.

\subsection{Robustness analysis in presence of uncertainty of $(\mp \mathbf{0 . 0 3})$}

Lastly, the robustness of the system to variations in the system model is examined. As described in Section (2), the model state space parameters can vary with certain bounded values, the robust performance is analyzed for perturbations of ( $\bar{\mp} 3 \%)$ of the nominal system model parameters values, as in $(\mathrm{A}=\mathrm{A} \pm 0.03 * \mathrm{~A})$, for testing the power of the designed robust controller. In simulation, these uncertain models are compared to the original models of the system. Four sets of experiments have been conducted based on the PID controller types; interactive PID, NPID, 2DoFPID and interactive
Table 4. The PID controllers type Performance comparison with disturbance $(0.5)$ and measurement noise $(0.02)$

\begin{tabular}{|c|c|c|c|c|c|c|}
\hline نे & 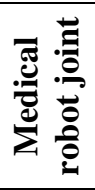 & 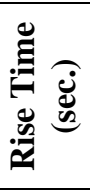 & 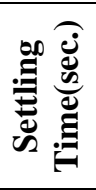 & 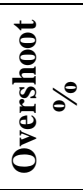 & 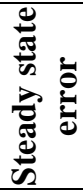 & 㻉 \\
\hline \multirow{2}{*}{ 冚 } & $\begin{array}{c}1^{\text {st }} \\
\text { Joint }\end{array}$ & $\begin{array}{c}0.08 \\
2\end{array}$ & & 32.4 & 0.02 & $\begin{array}{c}57.2 \\
5\end{array}$ \\
\hline & $\begin{array}{c}2^{\text {nd }} \\
\text { Joint }\end{array}$ & $\begin{array}{c}0.15 \\
2\end{array}$ & 2.6 & --- & 0.04 & $\begin{array}{c}55.3 \\
1\end{array}$ \\
\hline \multirow{2}{*}{ 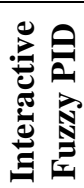 } & $\begin{array}{c}1^{\text {st }} \\
\text { Joint }\end{array}$ & $\begin{array}{c}0.16 \\
9 \\
\end{array}$ & 2.55 & --- & $\begin{array}{c}0.00 \\
4 \\
\end{array}$ & $\begin{array}{c}37.4 \\
8 \\
\end{array}$ \\
\hline & $\begin{array}{c}2^{\text {nd }} \\
\text { Joint }\end{array}$ & $\begin{array}{c}0.18 \\
2\end{array}$ & 2.4 & --- & 0.02 & $\begin{array}{c}37.4 \\
8\end{array}$ \\
\hline \multirow{2}{*}{$\frac{2}{\bar{z}}$} & $\begin{array}{c}1^{\text {st }} \\
\text { Joint }\end{array}$ & $\begin{array}{c}0.12 \\
3 \\
\end{array}$ & 2.8 & 19.7 & 0.02 & $\begin{array}{c}270 . \\
9\end{array}$ \\
\hline & $\begin{array}{c}2^{\text {nd }} \\
\text { Joint }\end{array}$ & $\begin{array}{c}0.12 \\
6\end{array}$ & 2.7 & --- & 0.02 & $\begin{array}{c}293 . \\
3\end{array}$ \\
\hline \multirow{2}{*}{$\frac{\hat{2}}{\frac{1}{8}}$} & $\begin{array}{c}1^{\text {st }} \\
\text { Joint }\end{array}$ & $\begin{array}{c}0.01 \\
1\end{array}$ & 3.1 & 20.3 & $\begin{array}{c}0.00 \\
5\end{array}$ & $\begin{array}{l}2.50 \\
1 \mathrm{e}+3\end{array}$ \\
\hline & $\begin{array}{c}2^{\text {nd }} \\
\text { Joint }\end{array}$ & $\begin{array}{c}0.00 \\
3 \\
\end{array}$ & 2.3 & 8.26 & 0001 & $\begin{array}{l}2.49 \\
6 e+3\end{array}$ \\
\hline
\end{tabular}

Fuzzy PID and for both medical robot joints as illustrated in Fig. (19), (20), (21) and (22).

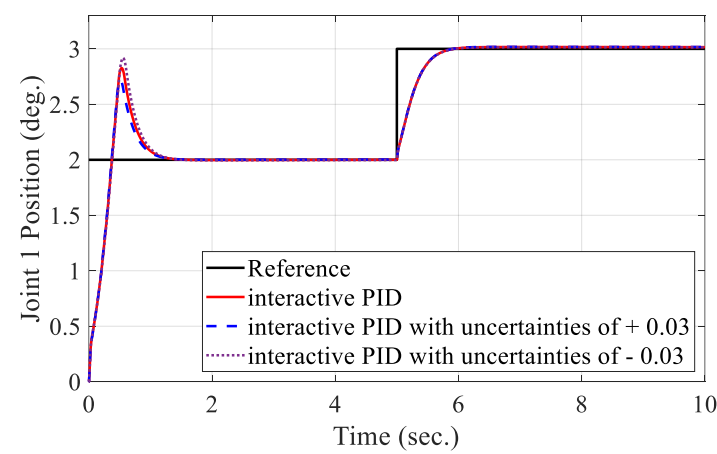

(a)

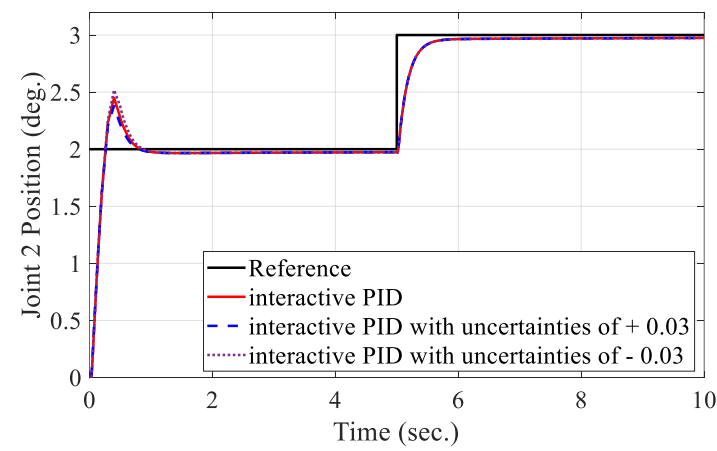

(b)

Figure. 19 The PID controllers with interaction response with the addition of $\mp 0.03$ uncertainties (a) for the medical robot $1^{\text {st }}$ joint and and (b) for the medical robot $2^{\text {nd }}$ joint 


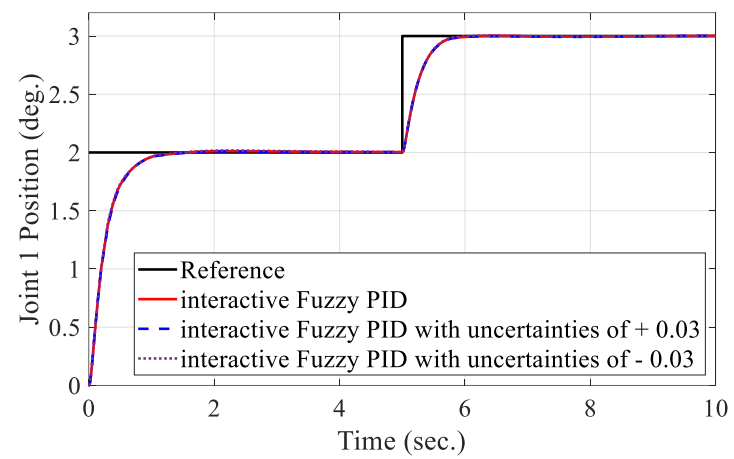

(a)

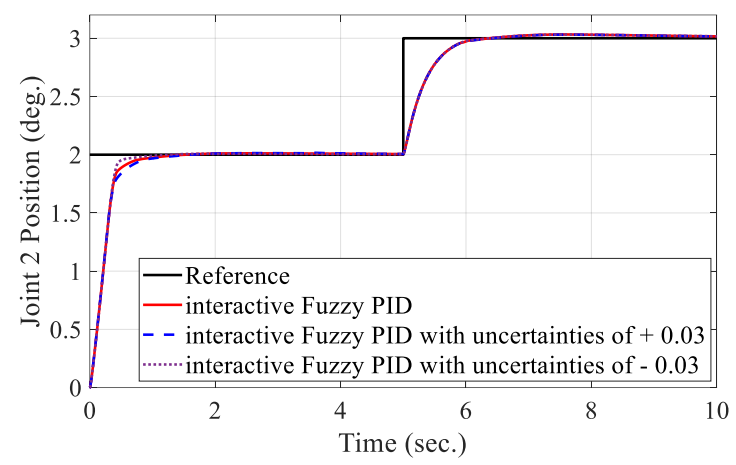

(b)

Figure. 20 The Fuzzy PID controllers with interaction response with the presence of $\mp 0.03$ uncertainties: (a) for the medical robot $1^{\text {st }}$ joint and (b) for the medical robot $2^{\text {nd }}$ joint

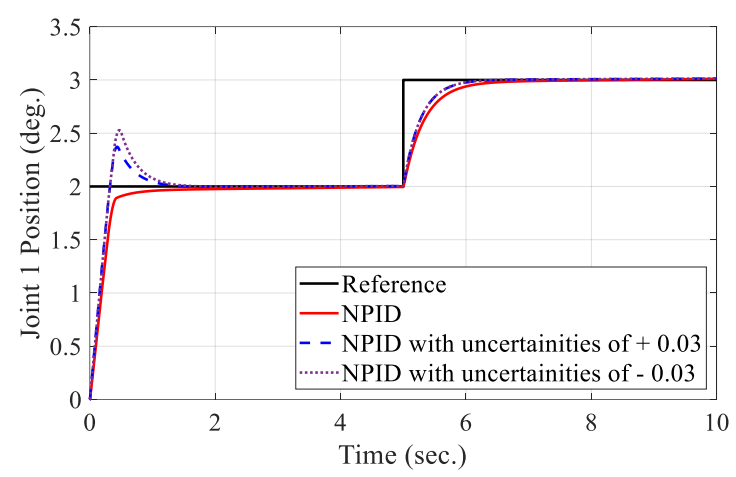

(a)

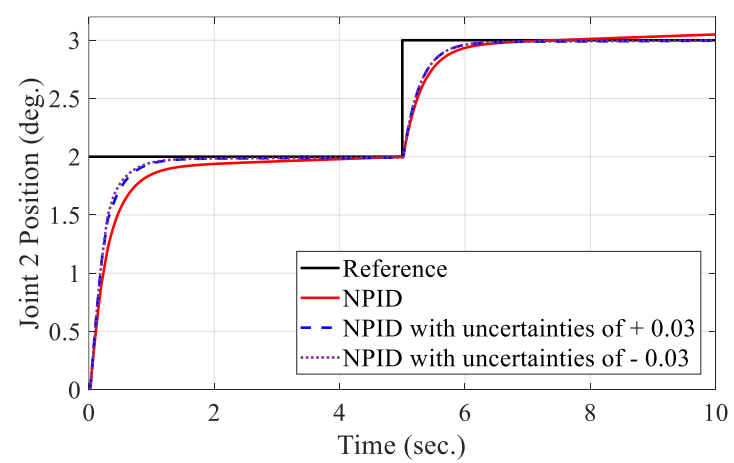

(b)

Figure. 21 The NPID controllers response with the addition of $\mp 0.03$ uncertainties: (a) for the medical robot $1^{\text {st }}$ joint and (b) for the medical robot $2^{\text {nd }}$ joint

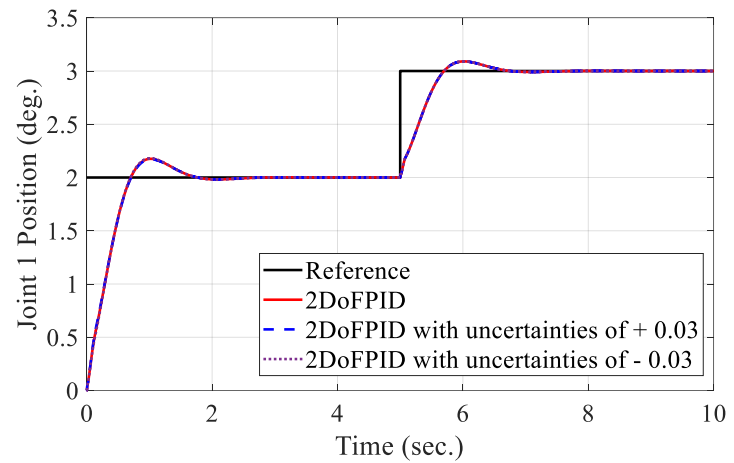

(a)

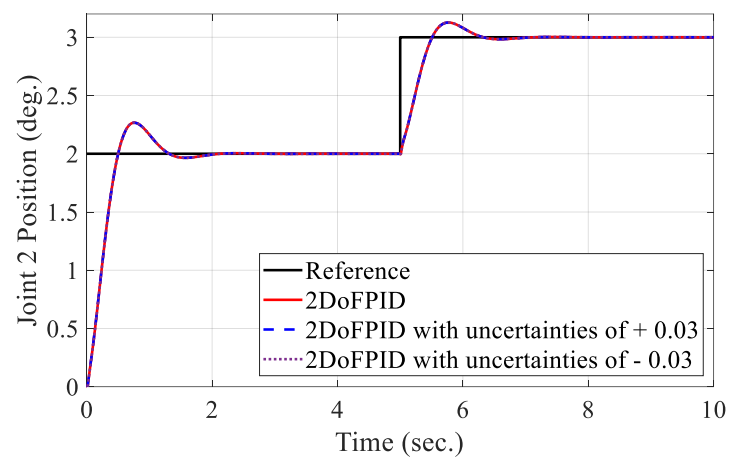

(b)

Figure. 22 The 2DoFPID controllers response with the addition of $\mp 0.03$ uncertainties: (a) for the medical robot $1^{\text {st }}$ joint and (b) for the medical robot $2^{\text {nd }}$ joint

Table 5. The PID controllers type Performance comparison with uncertainties of $\mp 0.03$

\begin{tabular}{|c|c|c|c|c|c|c|}
\hline تَ & 胥 & 总 & 兽 & $\frac{8}{0}$ & 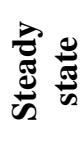 & 䅳 \\
\hline \multirow{2}{*}{ } & $\begin{array}{c}1^{\text {st }} \\
\text { Join }\end{array}$ & $\begin{array}{c}0.08 \\
8\end{array}$ & 1.5 & 1.86 & 0.02 & $\begin{array}{c}48.69 \\
3\end{array}$ \\
\hline & $\begin{array}{c}2^{\text {nd }} \\
\text { Joint }\end{array}$ & 0.08 & 1.1 & 1.22 & 0.03 & $\begin{array}{c}46.33 \\
6\end{array}$ \\
\hline \multirow{2}{*}{ 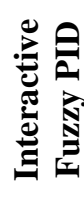 } & $\begin{array}{c}1^{\text {st }} \\
\text { Joint }\end{array}$ & $\begin{array}{c}0.18 \\
7\end{array}$ & 0.95 & --- & $\begin{array}{c}0.00 \\
1\end{array}$ & $\begin{array}{c}27.83 \\
1\end{array}$ \\
\hline & $\begin{array}{c}2^{\text {nd }} \\
\text { Joint }\end{array}$ & $\begin{array}{c}0.17 \\
1\end{array}$ & 1.03 & --- & $\begin{array}{c}0.01 \\
5\end{array}$ & $\begin{array}{c}27.93 \\
7\end{array}$ \\
\hline \multirow{2}{*}{$\frac{\hat{2}}{\bar{z}}$} & $\begin{array}{c}1^{\text {st }} \\
\text { Joint }\end{array}$ & $\begin{array}{c}0.12 \\
3\end{array}$ & 1.2 & 1.18 & 0.01 & $\begin{array}{c}178.0 \\
7\end{array}$ \\
\hline & $\begin{array}{c}2^{\text {nd }} \\
\text { Joint }\end{array}$ & $\begin{array}{c}0.12 \\
8 \\
\end{array}$ & 1.1 & --- & 0.02 & $\begin{array}{c}174.9 \\
1 \\
\end{array}$ \\
\hline \multirow{2}{*}{ 产 } & $\begin{array}{c}1^{\text {st }} \\
\text { Joint }\end{array}$ & $\begin{array}{c}0.01 \\
1 \\
\end{array}$ & 1.4 & 1.25 & $\begin{array}{c}0.00 \\
1 \\
\end{array}$ & $\begin{array}{c}2.5 \mathrm{e}+ \\
3 \\
\end{array}$ \\
\hline & $\begin{array}{c}2^{\text {nd }} \\
\text { Joint }\end{array}$ & $\begin{array}{c}0.00 \\
4\end{array}$ & 0.4 & 1.09 & $\begin{array}{c}0.00 \\
1\end{array}$ & $\begin{array}{c}2.5 \mathrm{e}+ \\
3\end{array}$ \\
\hline
\end{tabular}

It can be clearly noticed from these graphs, as well as the results shown in Table 5, that the proposed 
interactive Fuzzy PID controller in Fig. (20) can maintain better tracking performance as compared with the other controllers. Small changes can be seen in the tracking error. This undoubtedly assured the assumption that the proposed controller can be applied in uncertain conditions. It also demonstrates the assumption that it is not necessary to implement a precise model since reasonably considering imaginable uncertainties and mismatches.

The maximum stability is $1 \%$ of the designed controller performance even with the system's uncertainty that indicating the effectiveness of the used controllers except for the NPID controller that has some undesired overshoot in the addition of uncertainty as shown in Fig. (21).

\section{Conclusions}

This paper proposed the design of an interactive control mechanism based on RGA evaluation for medical robotic system. Well-tuned PID controllers have been developed for each element of the control structure. The goal is to provide a simple, efficient and robust control structure for systems with long and/or varying system's working conditions.

Different variations of parameters have been investigated to test the robustness of the proposed methods. The performance of all the designed controllers has been compared in terms of rising time, settling time, overshoot, steady-state error, and ISE calculations. The simulation results show that a considerable superiority can be noticed with the interactive Fuzzy PID controller, where better damping performance has been achieved as compared with the other PID controllers for all applied cases of simulation. Furthermore, the proposed interactive structure is robust against parameters variations.

The inclusion of other important factors will be considered in the future, as the presence of friction and time delays. In this case, different approach as active disturbance rejection control method will be considered to realize a robust optimal framework.

\section{Conflicts of Interest}

The authors declare no conflict of interest.

\section{Author Contributions}

Conceptualization, Safanah; methodology, Shaymaa and Safanah; software, Shaymaa and Safanah; validation, Shaymaa; formal analysis, Shaymaa and Safanah; investigation, Shaymaa and Safanah; resources, Shaymaa and Safanah; data curation, Shaymaa; writing original draft preparation,
Safanah; writing review and editing, Shaymaa and Safanah; visualization, Safanah and Shaymaa; supervision, Safanah; project administration, Shaymaa and Safanah; funding acquisition, not funded.

\section{References}

[1] A. Goswami and P. Vadakkepat, Humanoid Robotics: A Reference, Springer Nature B.V. 2019. ISBN 978-94-007-6046-2.

[2] E. R. Westervelt, J. W. Grizzle, C. Chevallereau, J. H. Choi, and B. Morris, "Feedback Control of Dynamic Bipedal Robot Locomotion", CRC Press is an Imprint of the Taylor \& Francis Group, 2007, ISBN 9781420053722.

[3] Y. B. Lari, M. Eghtesad, A. Khoogar, and A. M. Zadeh, "Tracking Control of A Human Swing Leg as a Double-Pendulum Considering SelfImpact Joint Constraint by Feedback Linearization Method", Journal of Control Engineering and Applied Informatics, Vol. 17, No. 1, 2015.

[4] Y. B. Lari, M. Eghtesad, A. Khoogar, and A. M. Zadeh, "Tracking Control of a Human Swing Leg Considering Self Impact Joint Constraint by Feedback Linearization Method", Control Engineering and Applied Informatics (CEAI), Vol. 17, No. 1, pp. 99-110, 2015.

[5] R. T. Yunardi, A. A. Firdaus, and E. I. Agustin, "Robotic Leg Design to Analysis the Human Leg Swing from Motion Capture", Bulletin of Electrical Engineering and Informatics, Vol. 6, No. 3, pp. 256-264, 2017.

[6] W. Huo, S. Mohammed, Y. Amirat, and K. Kong, "Fast Gait Mode Detection and Assistive Torque Control of an Exoskeletal Robotic Orthosis for Walking Assistance", IEEE Transactions on Robotics, Vol. 34, No. 4, 2018.

[7] H. I. Ali and A. J. Abdulridha, "State Feedback Sliding Mode Controller Design for Human Swing Leg System", Al-Nahrain Journal for Engineering Sciences, Vol. 21, Issue 1, pp. 5159, 2018.

[8] H. I. Ali and A. J. Abdulridha, "H-infinity Based Full State Feedback Controller Design for Human Swing Leg", Engineering and Technology Journal, Vol. 36, No. 3, pp. 350-357, 2018.

[9] H. I. Ali, A. F. Hasan, and H. M. Jassim, "Optimal H2PID Controller Design for Human Swing Leg System Using Cultural Algorithm", Journal of Engineering Science and Technology Vol. 15, No. 4, pp. 2270-2288, 2020. 
[10] H. I. Ali and A. J. Abdulridha, "H-infinity Sliding Mode Controller Design for a Human Swing Leg System", Al-Nahrain Journal for Engineering Sciences, Vol. 23, No. 2, pp. 117126, 2020.

[11] S. S. Ali, S. M. Raafat, and A. A. Khazraji, "Improving the performance of medical robotic system using Ho loop shaping robust controller", International Journal of Modelling, Identification and Control, Vol. 34, No. 1, pp. 312, 2020.

[12] Xi. Jing, H. Gao, Z. Chen, and Y. Wang, "A Recursive Dynamic Modeling and Control for Dual-arm Manipulator With Elastic Joints", IEEE Access, Vol. 8, 2020.

[13] J. Guo, "Robust Tracking Control of Variable Stiffness Joint Based on Feedback Linearization and Disturbance Observer With Estimation Error Compensation", IEEE Access, Vol. 8, 2020.

[14] J. Wang, J. Liu, G. Zhang, and S. Guo, "Periodic event-triggered sliding mode control for lower limb exoskeleton based on human-robot cooperation", ISA Transactions, Vol. 31, 2021.

[15] C. Mobile, J. Park, S. Park, C. Kim, J. H. Park, and J. Choi, "Design and Control of a Powered Lower Limb Orthosis Using a CableDifferential Mechanism", IEEE Access, Vol. 9, 2021.

[16] A. S. Wardhana, M. Ashari, and H. Suryoatmojo, "Optimal Control of Robotic Arm System to Improve Flux Distribution on Dual Parabola Dish Concentrator", International Journal of Intelligent Engineering and Systems, Vol. 13, No. 1, pp. 364-378, 2020.

[17] H. Rahali, S. Zeghlache, and L. Benyettou, "Fault Tolerant Control of Robot Manipulators Based on Adaptive Fuzzy Type-2 Backstepping in Attendance of Payload Variation", International Journal of Intelligent Engineering and Systems, Vol. 14, No. 4, pp. 312-325, 2021.

[18] H. A. R. Akkar and S. Q. G. Haddad, "Design Stable Controller for PUMA 560 Robot with PID and Sliding Mode Controller Based on PSO Algorithm", International Journal of Intelligent Engineering and Systems, Vol. 13, No. 6, pp. 487-499, 2020.

[19] V. M. Alfaro and R. Vilanova, "ModelReference Robust Tuning of PID Controllers", Springer International Publishing, 2016, ISBN 978-3-319-28211-4.

[20] G. G. Jin and Y. D. Son, "Design of a Nonlinear PID Controller and Tuning Rules for First-Order Plus Time Delay Models", Studies in
Informatics and Control, Vol. 28, No. 2, pp. 157-166, 2019.

[21] M. King, "Process Control A Practical Approach, Second edition.", Chichester, West Sussex, United Kingdom: John Wiley \&ons Inc., 2016.

[22] M. A. Mola, M. Mailah, A. H. Muhaimin, M. Y. Abdullah, and P. M. Samin, "Fuzzy-based PID with iterative learning active force controller for an anti-lock brake system", International Journal of Simulation: Systems, Science \& Technology, Vol. 13, No. 3, pp. 35-41, 2013.

[23] K. Ogata, Modern Control Engineering, $3^{\text {rd }}$ ed. Upper saddle River, NJ: Prentice Hall, 1997. 